\title{
Comparison of spontaneous and induced sputum for investigation of airway inflammation in chronic obstructive pulmonary disease
}

\author{
A Bhowmik, T A R Seemungal, R J Sapsford, J L Devalia, J A Wedzicha
}

\begin{abstract}
Background-Although sputum induction is used as a technique to investigate lower airway inflammation in asthmatic subjects, advantages over spontaneous sputum in patients with chronic obstructive pulmonary disease (COPD) have not been investigated.

Methods-Samples of spontaneous sputum and sputum induced with $3 \%$ hypertonic saline for 14 minutes were collected from 27 patients with chronic obstructive pulmonary disease (COPD) who usually produced spontaneous sputum. Spirometric indices and oxygen saturation $\left(\mathrm{SaO}_{2}\right)$ were measured at seven minute intervals. The spontaneous, seven and 14 minute sputum samples were analysed for total and differential cell counts, cell viability, and interleukin 8 levels.
\end{abstract}

Results-Analysis of the sputum revealed that median cell viability was higher in the seven minute $(62.8 \% ; p=0.004)$ and 14 minute $(65 \% ; p=0.001)$ induced sputum samples than in spontaneous sputum $(41.2 \%)$. There was no significant difference in total and differential cell counts or in interleukin 8 levels between spontaneous and induced sputum. During the sputum induction procedure the mean (SD) fall in forced expiratory volume in one second $\left(\mathrm{FEV}_{1}\right)$ was 0.098 (0.111) 1 (p < 0.001 ) and in forced vital capacity (FVC) was $0.247(0.233) 1(p<0.001)$. There was a small but significant fall in $\mathrm{SaO}_{2}$ during sputum induction $(p=0.03)$.

Conclusions-Induced sputum contains a higher proportion of viable cells than spontaneous sputum. There are no significant differences between the sputum samples obtained at seven minutes and at 14 minutes of hypertonic saline nebulisation. Sputum induction is safe and well tolerated in patients with COPD.

(Thorax 1998;53:953-956)

Keywords: chronic obstructive pulmonary disease; induced sputum; airway inflammation

Examination of induced sputum has been used for some years as a diagnostic technique to investigate lower airway inflammation. ${ }^{1-3}$ With sputum induction, samples can be obtained from the lower airways with minimal discomfort to the patient. In asthma this technique is now well established as a relatively safe, non-invasive, repeatable and valid method, ${ }^{4-6}$ though there is little information on its use or safety in patients with chronic obstructive pulmonary disease (COPD). ${ }^{7}$

Many patients with COPD produce spontaneous sputum but there has been no comparison made with sputum obtained by induction in this group. Induced sputum in asthmatic patients contains a higher proportion of viable cells and thus is preferable to spontaneous sputum. ${ }^{2}$ Induced sputum may be particularly useful in those patients with COPD who do not produce spontaneous sputum, or those who have significantly impaired lung function or are suffering from exacerbations and will not tolerate invasive procedures such as bronchoscopy.

In this study we have investigated the technique of sputum induction in a group of patients with COPD who usually produce spontaneous sputum. The induced and spontaneous sputum samples obtained were compared with respect to cell viability, total and differential cell counts, and levels of interleukin 8 , a cytokine found in previous studies to be raised in the sputum of patients with COPD. ${ }^{7}$ We have also investigated the safety of the procedure.

\section{Methods}

PATIENTS

Twenty seven patients with a diagnosis of COPD who gave a history of daily sputum production volunteered to participate in this study. COPD was defined as forced expiratory volume in one second $\left(\mathrm{FEV}_{1}\right)$ less than $70 \%$ of predicted for age and height, and salbutamol reversibility less than $15 \%$ or $200 \mathrm{ml}$ with airflow obstruction evidenced by an $\mathrm{FEV}_{1}$ / forced vital capacity (FVC) ratio of $<70 \%$. Patients with a history of asthma, bronchiectasis, carcinoma of the bronchus, or other significant respiratory disease were excluded. Eight of the 27 patients were current smokers at the time of recruitment, a further 17 being former smokers. Twenty six of the 27 were on inhaled corticosteroids, one also being on oral steroids for arthritis. At recruitment baseline measurements were made of $\mathrm{FEV}_{1}, \mathrm{FVC}$, and peak flow by rolling seal spirometer (SensorMedics Ltd, Yorba Linda, California, USA), reversibility to salbutamol, and ear lobe capillary blood gas tensions (Model 278 Blood Gas Analyser, Ciba-Corning, Medfield, Massachusetts, USA).

The study was approved by the City and East London Health Authority research ethics committee and written informed consent was obtained from each patient. 
COLLECTION OF SPONTANEOUS SPUTUM

Patients arrived at the clinic in the morning. Measurement of oxygen saturation (Minolta Pulsox 7, DeVilbiss Healthcare, Middlesex, UK) and spirometric tests were performed on arrival and repeated 10 minutes after premedication with $200 \mu \mathrm{g}$ inhaled salbutamol via a multidose inhaler. Patients were instructed to blow their noses and rinse their mouths out with water before expectorating sputum into a sterile pot.

SPUTUM INDUCTION

Nebulisation with 3\% saline was commenced using a procedure modified from that of Pin et $a l^{1}$ using the DeVilbiss UltraNeb2000 ultrasonic nebuliser. This nebuliser produced an aerosol output of approximately $2 \mathrm{ml} / \mathrm{min}$ with a mean particle size of $0.5-5 \mu \mathrm{m}$ in diameter. After seven minutes of nebulisation measurement of oxygen saturation and spirometric tests were performed and nebulisation continued if the $\mathrm{FEV}_{1}$ had not fallen by more than $20 \%$. After a further seven minutes the measurements were repeated and the procedure stopped. As before, patients were instructed to blow their noses and rinse their mouths out with water before expectorating sputum. Sputum samples collected during the first seven minutes and during the second seven minutes of the procedure were placed in separate sputum pots.

\section{SPUTUM EXAMINATION}

Sputum samples were examined as soon as possible, within two hours, adapting methods previously evaluated. ${ }^{168}$ The weight of the total sample was recorded. The sputum was then separated from contaminating saliva by macroscopic examination using a pair of disposable plastic forceps. The selected portion of the sputum was placed in a preweighed tube and the weight of the selected portion of the sputum recorded. The sputum was then mixed with four times its weight of freshly prepared $0.1 \%$ dithiothreitol solution made by mixing the dithiothreitol powder with Hank's balanced salt solution (HBSS). This was vortexed for 15 seconds and then rocked for 15 minutes. A weight of HBSS equal to that of the sputum plus dithiothreitol was then added and the whole mixture rocked for another five minutes. The suspension was then filtered through $50 \mu \mathrm{m}$ nylon gauze to remove mucus and debris without removing any of the cells and centrifuged at $790 \mathrm{~g}(2000 \mathrm{rpm})$ for 10 minutes. This resulted in the formation of a cell pellet and a supernatant solution. The supernatant was decanted off and stored at $-70^{\circ} \mathrm{C}$ for future analysis and the cell pellet was resuspended in 400-1200 $\mu \mathrm{l}$ (depending on macroscopic estimation of the size of the cell pellet) of HBSS. The total cell count was determined with a Neubauer haemocytometer using the trypan blue exclusion method to determine cell viability, blue cells being counted as non-viable. The absolute number of non-squamous cells per gram of the original sputum sample was determined and the percentage of viable and non-viable cells obtained. The cell suspension
Table 1 Mean (SD) baseline physiological characteristics of patients with COPD

\begin{tabular}{ll}
\hline Number & $27(21 \mathrm{M}, 6 \mathrm{~F})$ \\
Age (years) & $66.3(8.1)$ \\
$\mathrm{FEV}_{1}(1)$ & $0.95(0.37)$ \\
$\mathrm{FEV}_{1}(\%)$ & $38.2(14.6)$ \\
$\mathrm{FVC}_{(1)}(1)$ & $2.11(0.62)$ \\
$\mathrm{SaO}_{2}(\%)$ & $94.08(2.91)$ \\
$\mathrm{PaO}_{2}(\mathrm{kPa})$ & $8.61(1.02)$ \\
$\mathrm{PaCO}_{2}(\mathrm{kPa})$ & $5.99(0.98)$ \\
\hline
\end{tabular}

was then mixed with HBSS to obtain a count of $0.6-1.0 \times 10^{6}$ cells $/ \mathrm{ml}$ of the suspension. Cytospins were then made using a Cytotek cytocentrifuge. The cytospin slides were stained with DiffQuik to obtain differential cell counts made by counting 400 cells per slide. Levels of IL-8 in the supernatant samples were measured using a quantitative sandwich immunoassay. A monoclonal antibody specific for the cytokine was precoated onto a microtitre plate and standards and samples added. After washing, an enzyme linked polyclonal antibody was added followed by a substrate solution for colour development and intensity reading ( $R \& D$ Systems Europe, Abingdon, Oxon, UK).

STATISTICAL ANALYSIS

Spirometric results and blood gas tensions are expressed as means and standard deviations. Data pertaining to sputum are expressed as medians and ranges. The Wilcoxon signed rank test was used to compare the cell viability in the spontaneous, seven minute and 14 minute sputum samples and paired $t$ tests to compare the physiological measurement data for the different points in time. The statistical package SPSS was used for data analysis.

\section{Results}

Baseline characteristics of the patients are shown in table 1. The mean (SD) $\mathrm{FEV}_{1}$ was 0.95 (0.37) 1 . The mean (SD) $\mathrm{FEV}_{1} / \mathrm{FVC}$ ratio was $45.3(12.9) \%$.

The median weights of total (and selected) sputum obtained spontaneously and at seven and 14 minutes were $1.6(0.4) \mathrm{g}, 4.0(0.6) \mathrm{g}$, and $4.1(0.5) \mathrm{g}$, respectively. The sputum samples analysed had a median squamous cell contamination of $6.4 \%$ in spontaneous sputum (12 samples containing more than $10 \%), 6.0 \%$ in induced sputum at seven minutes (eight samples containing more than $10 \%$ ), and $4.6 \%$ in induced sputum at 14 minutes (eight samples containing more than $10 \%$ ). The volumes obtained were, however, variable.

Significantly higher cell viability was obtained in induced sputum than in spontaneous sputum (table 2). The median viability was $41.2 \%$ in spontaneous sputum, $62.8 \%$ in induced sputum at seven minutes, and $65 \%$ in induced sputum at 14 minutes. The difference between the median viabilities in spontaneous and seven minute sputum samples was $21.6 \%$ $(p=0.004)$, and between spontaneous and 14 minute sputum samples was $23.8 \%$ ( $\mathrm{p}=$ $0.001)$. Differential counts could be performed on 18 of the 25 spontaneous sputum samples, 23 of the 27 sputum samples obtained at seven minutes, and 22 of the 25 sputum samples obtained at 14 minutes. Counts could not be 
Table 2 Comparison of cell counts, cell viability, and interleukin 8 levels in spontaneous and induced sputum samples $(n=27)$

\begin{tabular}{|c|c|c|c|}
\hline & \multicolumn{3}{|c|}{ Median (interquartile range) } \\
\hline & Spontaneous sputum & $\begin{array}{l}\text { Induced sputum at } \\
7 \text { minutes }\end{array}$ & $\begin{array}{l}\text { Induced sputum at } \\
14 \text { minutes }\end{array}$ \\
\hline $\begin{array}{l}\text { Total counts } \times 10^{6} \text { cells } / \mathrm{g} \\
\text { sputum }\end{array}$ & $3.43(1.66-7.17)$ & $1.91(0.76-5.15)$ & $2.10(1.31-5.91)$ \\
\hline Neutrophils (\%) & $88.0(72.5-89.5)$ & $88.8(70.0-93.5)$ & $81.3(77.8-91.8)$ \\
\hline Macrophages (\%) & $11.0(6.3-23.5)$ & $10.3(4.8-22.5)$ & $9.0(6.5-18.3)$ \\
\hline Lymphocytes (\%) & $1.5(0.8-3.8)$ & $2.0(0.5-5.3)$ & $2.0(1.0-2.5)$ \\
\hline Eosinophils (\%) & $0.3(0.3-0.5)$ & $0.3(0.0-1.3)$ & $0.5(0.0-0.8)$ \\
\hline Cell viability (\%) & $41.2(11.7-71.8)$ & $62.8(35.5-76.5)^{\star}$ & $65.0(54-76.2)^{\star}$ \\
\hline Interleukin $8(\mathrm{pg} / \mathrm{ml})$ & 5475 (1265-9083) & $4288(2653-6282)$ & $3847(747-8539)$ \\
\hline
\end{tabular}

${ }^{\star} \mathrm{p}=0.001$ compared with spontaneous sputum sample.

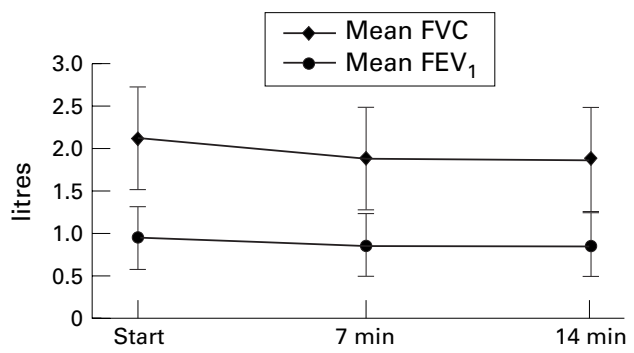

Figure 1 Changes in FEV $V_{1}$ and FVC at start of procedure and after seven and 14 minutes of sputum induction.

performed on the other 14 slides due to poorly defined cell morphology. It was found that the median cell viability (the number of viable non-squamous cells counted expressed as a percentage of the total non-squamous cell count) in the 63 slides in which differential counts could be performed was $63.1 \%$, whereas that in the 14 slides in which counts could not be performed was $27.5 \%$. This difference was found to be significant using the Mann-Whitney test $(\mathrm{p}<0.001)$.

There was no significant difference between the total or differential cell counts, or the levels of IL-8 in spontaneous and induced sputum samples (table 2). A set of standard samples of IL-8 was assayed with $0.04 \%$ dithiothreitol to ascertain whether this interfered with the assay (this being approximately the amount of dithiothreitol found in the sputum supernatant samples). However, at this concentration there was no significant difference between the standard samples assayed with and without dithiothreitol.

There was a significant mean (SD) fall in $\mathrm{FEV}_{1}$ in the first seven minutes of 0.105 (0.094) 1 ( $\mathrm{p}<0.001$; fig 1$)$. The total fall over 14 minutes was $0.098(0.111) 1$, representing a fall of $11.7 \%(p<0.001)$. The FVC fell by 0.276 $(0.279) 1(\mathrm{p}<0.001)$ over the first seven minutes and $0.247(0.233) 1(\mathrm{p}<0.001)$ over the whole 14 minutes, representing a fall of $12 \%$. There was a very small fall in $\mathrm{SaO}_{2}$ at seven minutes of $0.63(1.39) \%(\mathrm{p}=0.02)$ and at 14 minutes of $0.056(1.26) \%(\mathrm{p}=0.03)$. Peak expiratory flow rates were not significantly changed with mean (SD) values at baseline, seven and 14 minutes of 2.71 (1.10) $1 / \mathrm{s}, 2.64$ (1.12) $\mathrm{l} / \mathrm{s}$, and $2.59(1.08) \mathrm{l} / \mathrm{s}$, respectively ( $\mathrm{p}=$ 0.33 for first seven minutes and 0.15 for whole duration).

All patients tolerated sputum induction well in the first seven minutes, with three of the 27 stopping before the full 14 minutes due to dys- pnoea (mean stoppage time $=10$ minutes), one stopping due to a fall in $\mathrm{FEV}_{1}$ of just over $20 \%$ at the end of seven minutes of induction, and one stopping due to a coincidental nose bleed (this patient had a history of frequent nose bleeds due to a vascular abnormality in his nasal mucosa). Only one of those who stopped complaining of dyspnoea felt that he needed to take a dose of his salbutamol inhaler and none of the subjects required nebulised salbutamol.

\section{Discussion}

This study showed that cell viability was significantly higher in induced sputum than in spontaneous sputum samples and there was no significant difference in total and differential cell counts and levels of IL- 8 between the different sputum samples. The technique of sputum induction was shown to be well tolerated in patients with COPD.

With increasing interest in the mechanisms of inflammation in patients with COPD, there is a need to obtain airway samples by a convenient and non-invasive technique. Sixty two percent of patients with COPD produce daily spontaneous sputum, ${ }^{9}$ but it is important that all patients with COPD, whether or not they produce spontaneous sputum, are studied with a standardised clinical sample. Patients with severe COPD are unable to tolerate bronchoscopic procedures. There are particular difficulties in evaluating patients who are suffering from exacerbations and in whom we need information about airway inflammatory changes. The procedure has potential as an investigatory tool in patients who do not produce sputum spontaneously. Sputum induction is thus particularly useful in obtaining clinical samples from these patients in order to provide specific information on cellular and molecular aspects of airway inflammation. These samples are also more concentrated and richer in airway secretions than those obtained by bronchoscopy. ${ }^{10}$

This study showed that there is a large variability in the total cell counts and this may reflect the variability in the physical properties of the sputum. Whereas some samples contained large amounts of tenacious mucus, much of which had to be filtered, other samples were more fluid and easily homogenised, leading to better cell recovery. The higher proportion of viable cells found in induced sputum may be explained by the fact that sputum induction causes the mobilisation of a newer cell population after an older, and perhaps dying, population of cells has been spontaneously expectorated. ${ }^{2}$

As previously shown, there was a relatively high proportion of neutrophils in the lower airway samples of patients with COPD which suggests that neutrophilic inflammation is the major factor in the pathology of the disease. ${ }^{11-13}$ Stãnescu et al have shown that airways obstruction and chronic expectoration, as well as rapid decline in $\mathrm{FEV}_{1}$, are associated with increased numbers of neutrophils in the sputum. ${ }^{12}$ The sputum induction procedure itself is considered a stimulus for the appearance of greater numbers of neutrophils in the 
sputum, but these effects are seen some hours after nebulisation. ${ }^{14}$ We have not taken repeated sputum samples within the space of a few hours but an interval of at least one week between nebulisations is desirable to achieve meaningful results. ${ }^{15}$ Eosinophil and lymphocyte counts were low but variable in individual patients. A drawback of the technique of sputum analysis can be the relative difficulty in accurate recognition of lymphocytes on cytospin preparations. ${ }^{5}$ We found no differences in the differential counts between spontaneous and induced sputum and the results from induced sputum at seven and 14 minutes were similar. It may be possible, therefore, to stop sputum induction when an appropriate volume of sample has been obtained without the need to carry on for the full period. Another recent study ${ }^{16}$ has, however, found significant differences in these counts. This may be partly due to the fact that this particular study looked at normal and asthmatic subjects rather than patients with COPD, and the sputum induction procedure was continued for significantly longer and with higher concentrations of hypertonic saline in the latter stages.

Dithiothreitol breaks up disulphide bonds, which are present in IL-8, and may thus theoretically interfere with the assay. ${ }^{7}$ We found that, as other work has shown, IL- 8 measurements were not affected by the presence of dithiothreitol in the sputum supernatants at the concentrations used here. ${ }^{17}$ Higher concentrations of dithiothreitol used by some groups affect the concentration of IL- 8 and would require an adjustment when calculating levels. In such a case an alternative method of sputum processing has been used with ultracentrifugation to separate the sol phase of the sputum from the cells.

The procedure of sputum induction in this group of patients was well tolerated, although three of the patients experienced symptoms and there was an asymptomatic fall in $\mathrm{FEV}_{1}$ of just over $20 \%$ in another. Induced sputum was also relatively easy to obtain in these patients with COPD compared with asthmatic subjects, ${ }^{1} 14$ minutes of nebulisation producing an adequate sample in most cases.

This study shows that induced sputum is useful in practice as a method of providing standardised lower airway samples in patients with COPD, especially for clinical investigations. With the technique, much valuable information will be obtained about airway inflammatory changes and response to treatment without requiring invasive procedures.

The authors thank DeVilbiss UK for the loan of the Ultraneb 2000 nebuliser used in this study.

1 Pin I, Gibson PG, Kolendowicz R, et al. Use of induced sputum cell counts to investigate airway inflammation in asthma. Thorax 1992;47:25-9.

2 Pizzichini MMM, Popov TA, Efthimiadis A, et al. Spontaneous and induced sputum to measure indices of airway inflammation in asthma. Am f Respir Crit Care Med 1996; 154:866-9.

3 Fahy JV, Liu J, Wong H, et al. Cellular and biochemical nalysis of induced sputum from asthmatic and from healthy subjects. Am Rev Respir Dis 1993;147:1126-31.

4 Veen JCCM, de Gouw HWFM, Mits HH, et al. Repeatability of cellular and soluble markers of inflammation in induced sputum from patients with asthma. Eur Respir $\mathcal{F}$ 1996;9:2441-7.

5 Pizzichini E, Pizzichini MMM, Efthimiadis A, et al. Indices of airway inflammation in induced sputum: reproducibility and validity of cell and fluid-phase measurements. $A m \mathcal{F}$ Respir Crit Care Med 1996;154:308-17.

6 Popov T, Gottschalk R, Kolendowicz R, et al. The evaluation of a cell dispersion method of sputum examinaevaluation of a cell dispersion method
tion. Clin Exp Allergy 1994;24:778-83.

7 Keatings VM, Collins PD, Scott DM, et al. Differences in interleukin-8 and tumour necrosis factor in induced sputum from patients with chronic obstructive pulmonary disease and asthma. Am $\mathcal{F}$ Respir Crit Care Med 1996;153: $530-4$.

8 Pizzichini E, Pizzichini MMM, Efthimiadis A, et al. Measurement of inflammatory indices in induced sputum: effects of selection of sputum to minimize salivary contamination. Eur Respir f 1996;9:1174-80.

9 Seemungal TAR, Donaldson GC, Paul EA, et al. Effect of exacerbation on quality of life in patients with chronic exacerbation on quality of life in patients with chronic
obstructive pulmonary disease. Am $\not$ f Respir Crit Care Med 1998;157:1418-22.

10 Fahy JV, Wong H, Liu J, et al. Comparison of samples collected by sputum induction and bronchoscopy from asthmatic and healthy subjects. Am $\mathcal{F}$ Respir Crit Care Med 1995;152:53-8.

11 Lacoste YJ, Bousquet J, Chanez P, et al. Eosinophilic and neutrophilic inflammation in asthma, chronic bronchitis and chronic obstructive pulmonary disease. $\mathcal{F}$ Allergy Clin Immunol 1993;92:537-48.

12 Stãnescu D, Sanna A, Veriter C, et al. Airways obstruction, chronic expectoration, and rapid decline of $\mathrm{FEV}_{1}$ in smokers are associated with increased levels of sputum ers are associated with increased

13 Linden M, Rasmussen JB, Piitulainen E, et al. Airway nflammation in smokers with nonobstructive and obstrucive chronic bronchitis. Am Rev Respir Dis 1993;148:122632

14 Nightingale JA, Rogers DF, Barnes PJ. Effect of repeated putum induction on cell counts in normal volunteers. Thorax 1998;53:87-90.

15 Pavord ID. Sputum induction to assess airway inflammation: is it an inflammatory stimulus? Thorax 1998;53:79-80.

16 Holz O, Jorres RA, Koschyk S, et al. Changes in sputum composition during sputum induction in healthy and asthmatic subjects. Clin Exp Allergy 1998;28:284-92

17 Efthimiadis A, Pizzichini MMM, Pizzichini E, et al. Induced sputum cell and fluid-phase indices of inflammation: comparison of treatment with dithiothreitol vs phosphatebuffered saline. Eur Respir f 1997;10:1336-40. 